\title{
Apraxia de la deglución y lenguaje asociado con encefalitis autoinmune por anticuerpos anti-NMDA, reporte de un caso.
}

\section{Case report: Apraxia of swallowing and language associated with autoimmune encephalitis due to anti-NMDA antibodies.}

Pág. 24,30

Recibido: 11-05-2020

Aceptado: 11-06-2020

Dr. Ioav Chinchilla Tarnopolsky ${ }^{1}$

Dr. Sixto Bogantes Ledezma

1. Médico General,Trabajador independiente, Costa Rica.

2. Médico especialista del servicio de Neurología del Hospital Nacional de Niños, Caja Costarricense del Seguro Social.Costa Rica.

\section{RESUMEN}

Se presenta el caso de un niño de 5 años, conocido sano, que inicia con convulsiones focales motoras izquierdas que desarrolla alteraciones del ciclo de vigilia, trastornos de la personalidad, salivación, incapacidad para alimentarse, mutismo con comprensión verbal, un mes posterior a una infección de vías respiratorias. Ante la sospecha de una encefalitis autoinmune se corrobora la presencia de anticuerpos anti NMDA en LCR (líquido cefalorraquídeo). Se inicia terapia con inmunoglobulinas y esteroides. Evoluciona con una respuesta positiva pero fluctuante, persistiendo 12 meses posterior al egreso con severa disfunción deglutoria, expresión verbal limitada a 3 palabras y trastorno conductual con agresividad.

\section{ABSTRACT}

We present the case of a 5-year-old child, known healthy, who started with left focal motor seizures, sleep cycle and disorders, salivation and incapability to swallow, associated

with mutism but verbal understanding, a month after a respiratory tract infection. Autoimmune encephalitis diagnosis is confirmed with the presence of anti-NMDA antibodies in cerebrospinal fluid (CSF), and immunoglobulins

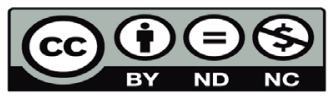


and steroids therapy were initiated. He showed a positive but fluctuating response, the child begins his recovery and leaves the hospital with improvement in his symptoms and general condition, although 12 months after discharge he remains with swallowing dysfunction, verbal production limited to 3 word but keeping good understanding and behavioral disorder with aggressiveness.

\section{PALABRAS CLAVE}

Encefalitis autoinmune, anti-MNDA, convulsión, trastorno neuropsiquiátrico, apraxia de deglución.

\section{INTRODUCCIÓN}

Las encefalitis autoinmunes son un conjunto de trastornos causados por anticuerpos contra receptores proteínicos de la membrana neuronal o sináptica, causando un amplio rango manifestaciones neurológicas y psiquiátricas complejas, incluyendo entre otros, déficit de memoria o cognitivos, psicosis, convulsiones, discinesias o estado de coma.

Aunque el grado de disfunción suele ser severo, los pacientes tienen una alta tasa de respuesta a la terapia inmunomoduladora o bien resección tumoral cuando éste se encuentra presente. Un inicio precoz de la terapia ha demostrado mejoras en la recuperación y sobrevida del paciente y una disminución en el riesgo de recaídas, por lo que es de suma importancia su sospecha y pronto diagnóstico.

\section{REPORTE DEL CASO}

Se presenta el caso de un masculino de 5 años, sin antecedentes perinatales 0 postnatales patológicos conocidos, con un desarrollo psicomotor dentro de límites normales, es referido al servicio de emergencias del Hospital Nacional de Niños de la Caja Costarricense del Seguro Social en enero del 2019, con historia de 3 semanas de evolución de convulsiones focales motoras izquierdas, con pérdida de conciencia, de duración variable, no relacionados a un cuadro febril o infeccioso actual.

A su ingreso se logran observar los episodios: convulsiones tónicas sostenidas del hemicuerpo izquierdo involucrando miembro superior, desviación de la comisura labial y parpadeo del ojo izquierdo, además de habla balbuceante, lesiones eritematosas orales con costra y sangrado al tacto, sin vesículas.

Al ingreso se tomaron hemograma, bioquímica, pruebas de función hepática y renal fueron normales, y se obtuvo una muestra de líquido cefalorraquídeo que presentó 0 leucocitos y el resto de los parámetros bioquímicos normales, así como la reacción de cadena de polimerasa (PCR) viral y bacteriano para herpes virus simple 1 y 2, enterovirus, citomegalovirus, varicela zoster, S. agalactiae, S. pneumoniae, $H$. influenzae, L. monocytogenes negativos. Se reserva una muezstra del LCR para posibles estudios posteriores.

Durante su internamiento, el paciente desarrolla discinesias en miembro superior izquierdo y episodios de irritabilidad e ira junto a una pérdida de la capacidad motora verbal y de comprensión. Por esta razón se inició terapia esteroidal, gammaglobulina endovenosa ( $6 \mathrm{gr}$ al día durante 5 días) y clobazam $10 \mathrm{mg}$ cada 12 horas oral.

Se complementan estudios con un electroencefalograma que demostró una actividad basal desestructurada con períodos 
de actividad lenta difusa, de predominio derecho y en cuadrantes posteriores. (imagen $1)$; imágenes por resonancia magnética (RMN) en la que no se observa ninguna anormalidad significativa (imagen 2).

Se realizó análisis inmunohistoquímico de LCR el cual evidenció la presencia de anticuerpos contra el receptor NMDA.

En los meses posteriores al egreso hospitalario, persistió con episodios de agresividad, alteraciones del patrón de sueño y poca producción verbal con adecuada comprensión. Además, incapacidad para deglutir alimentos, caracterizada por dificultad de masticar los alimentos y propulsarlos hacia la orofaringe y el esófago, sin episodios de broncoaspiración asociados. Se le realizaron múltiples estudios de imagen y neurofisiológicos, donde se descartó patología orgánica o disfunción muscular. En un esofagograma realizado, se observa el paso del medio de contraste a través del esófago de manera adecuada, sin desviación de su curso hacia la vía respiratoria o regurgitación de este (imagen 3).

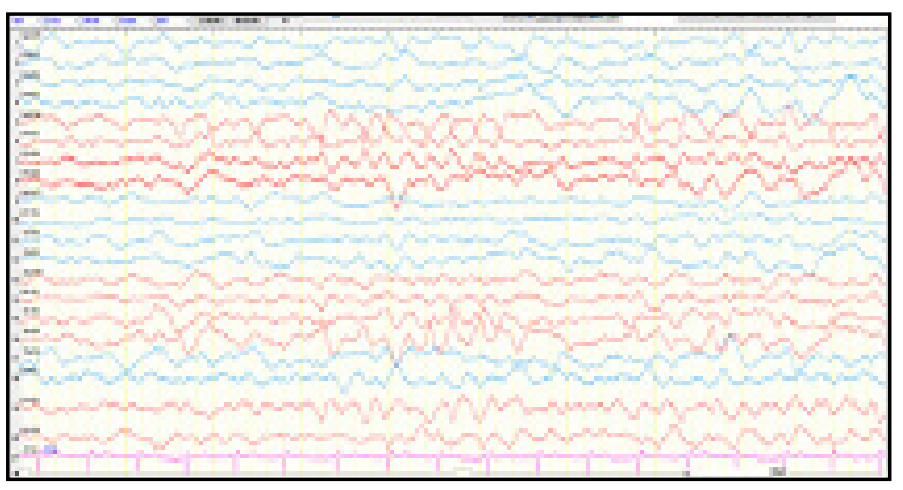

Imagen 1. EEG del 29/1/19 con espigas semi rítmicas frontocentrales derechas máximas F4.

\section{DISCUSIÓN}

\section{EPIDEMIOLOGÍA}

La incidencia general de encefalitis se describe en 5-8 casos por cada 100000 personas; sin documentarse una causa hasta en la mitad de los casos(6). En Costa Rica para el año 2017 la incidencia de encefalitis autoinmune se estima en 0,9 por 100000 niños menores de 13 años (10).

Dentro del espectro de la encefalitis autoinmune, la causa más común es por la presencia de anticuerpos anti-NMDAR(4,7). Afecta predominantemente infantes y adultos jóvenes (media 21 años), y principalmente mujeres en una proporción $4: 1$.

El $58 \%$ de las mujeres presentan un teratoma ovárico; en hombres y niños raramente se asocia con neoplasias(6). En este no se encontró neoplasia en los estudios iniciales ni luego de un año de seguimiento.

\section{MECANISMOS AUTOINMUNIDAD}

\section{PATOGÉNICOS}

El mecanismo por el cual los anticuerpos específicos se producen o llegan al cerebro no es conocido. Se ha postulado que la respuesta es iniciada por antígenos liberados durante la destrucción neuronal por un virus o por neoplasias.

Entre las principales causas infecciosas identificadas en paciente con encefalitis autoinmune son el Herpes simplex virus $y$ Mycoplasma pneumoniae. El tumor más frecuentemente asociado en mujeres es el teratoma ovárico (1). 


\section{MANIFESTACIONES CLÍNICAS}

Las encefalitis autoinmunes se caracterizan por un cuadro encefalopático asociado a trastornos neuropsiquiátricos. Generalmente tienen un inicio veloz, con un progreso de pocos días a semanas.

En niños y adolescentes, es más frecuente que se presenten con convulsiones y discinesias(9). En concordancia con lo descrito para la presentación pediátrica, el paciente aquí descrito, presentó un pródromo de malestar general, febrícula, que progresaron a crisis convulsivas y tal como ha descrito Álvarez y colaboradores, la pérdida de lenguaje en 12 de los 13 pacientes estudiados, "La disminución franca o pérdida de lenguaje observada en esta serie parece ser una característica propia de la forma infantil, pues se ve muy rara vez en pacientes adultos"(2). De manera sincrónica con la pérdida del lenguaje, el paciente presentó síntomas de disfunción extrapiramidal, entre ellos disquinesia y sialorrea, que evoluciona a una completa incapacidad de trasladar el bolo alimenticio hasta la orofaringe.

Esta disfunción deglutoria persiste un año después del inicio de los síntomas. La evolución de las convulsiones inicialmente se presentó como crisis focales motoras izquierdas, con un foco electroencefalógrafo en $\mathrm{C} 4$, sin embargo, en la evolución, las crisis pasaron a ser de sensación de disconfort torácico y activación autonómica.

\section{EXÁMENES DE LABORATORIO E IMÁGENES}

En los exámenes de laboratorios es posible encontrar leucocitosis. EI LCR es usualmente normal, aunque puede hallarse pleocitosis $(<100$ linfocitos/mm3) y anticuerpos específicos(4).
El estudio de imagen de elección es la RMN, que muestra alteraciones hasta en un $30 \%$ de los casos(4), con hiperintensidad cortical, subcortical y cerebelosa en T2/FLAIR.

En el electroencefalograma suele presentarse un enlentecimiento difuso, actividad desorganizada y actividad epileptógena.

\section{TRATAMIENTO}

Dada la poca experiencia mundial que existe en el manejo de la encefalitis autoinmune y la falta de estudios para validar su manejo, las recomendaciones actuales consisten en la resección tumoral cuando existe, y la inmunomodulación(4).

Los medicamentos usados son esteroides, la inmunoglobulina endovenosa y la plasmaféresis, de forma indistinta, aunque la producción de anticuerpos más allá de la barrera hematoencefálica podría explicar la poca respuesta en algunos casos a la plasmaféresis y la inmunoglobulina.En caso de mala respuesta, se recomienda el uso de rituximab, ciclofosfamida o ambos.

El rápido inicio de la terapia inmunomoduladora o la resección tumoral, permiten una recuperación más satisfactoria y menor riesgo de recurrencia (4).

En un estudio en el 2009, se documentó una recuperación de los síntomas más frecuente en pacientes que se les realizó resección de un tumor en comparación a los que no presentaron neoplasia (1). 


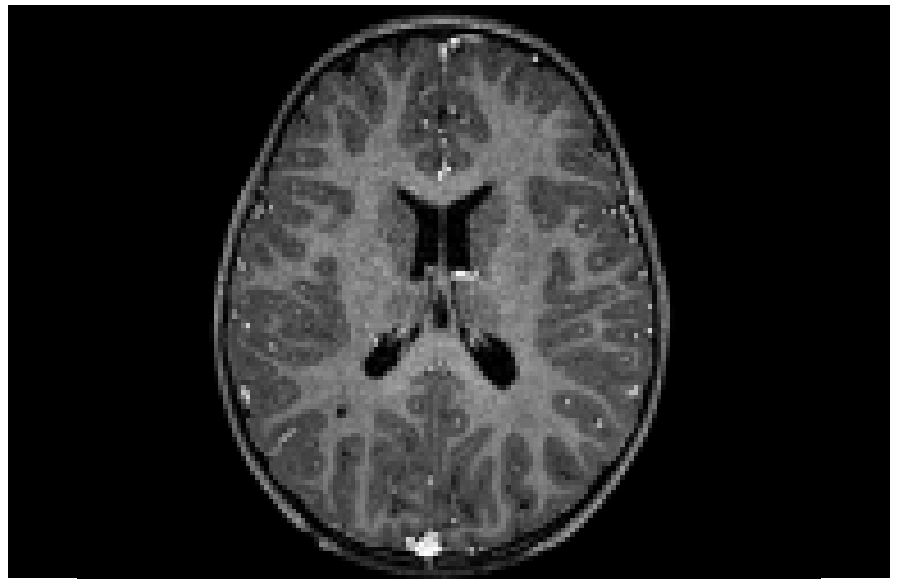

Imagen 2. Corte de la Resonancia Magnética del paciente. No se observa ninguna alteración significativa.

\section{APRAXIA DE LA DEGLUCIÓN}

La deglución en un complejo proceso en el cual el alimento es transportado de la cavidad oral hacia el estómago; involucra un componente voluntario y uno reflejo involuntario.

Todo el proceso deglutorio puede dividirse en una fase oral preparatoria, otra de transporte, una fase faríngea y finalmente la fase esofágica. La fase oral es esencialmente voluntaria, mientras que la faríngea y esofágica son involuntarias.

La disfagia orofaríngea, se define como la sensación subjetiva de dificultad para que el alimento pase desde la boca al estómago ocasionada por un trastorno de la motilidad orofaríngea (9). Trupe y colaboradores, estudió la apraxia del lenguaje y la deglución en adultos con eventos cerebrovasculares; identifican que los mecanismos de la deglución pueden verse afectados con lesiones hemisféricas uni 0 bilaterales (8), lo que evidencia la complejidad de este proceso. Además, indican que estos pacientes se encuentran en un riesgo aumentado de broncoaspiración.
Pérez-Aisa define la apraxia de la deglución como dificultad, retardo o imposibilidad de iniciar la fase oral. Por tratarse de una apraxia, se comprende que este trastorno se da durante la fase voluntaria de la deglución, excluyendo de esta manera, la fase faríngea, la cual se cree está controlada por un centro sensorial medular y se activa cuando el bolo pasa por cualquier punto entre los arcos anteriores palatinos y el borde inferior de la rama mandibular (9).

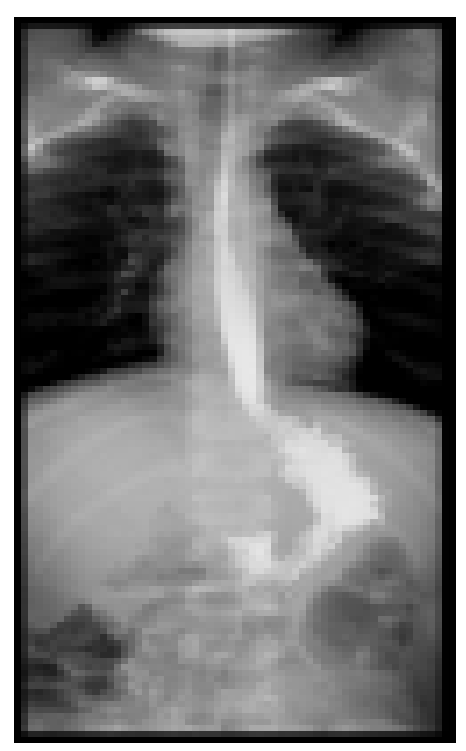

Imagen 3.

Extracto del esofagograma realizado al paciente.

Se logró determinar integridad de la fase faríngea de la deglución.

En el caso de este paciente, la presencia de crisis convulsivas con síntomas autonómicos, el foco epileptógeno frontocentral y la presencia de síntomas extrapiramidales sugieren un compromiso de varias redes neuronales, afectando la deglución voluntaria.

\section{CONCLUSIONES}

La encefalitis autoinmune, es una patología poco frecuente, cuyo diagnóstico va en aumento, gracias a los avances tecnológicos que permiten su diagnóstico precoz y preciso. El análisis diferencial para lograr identificar esta patología incluye una gran variedad de trastornos lo que 
retrasa el inicio de la terapia.

Dentro de la encefalitis autoinmune, la mediada por anti-NMDAR, es la más frecuente; y dado que posee una causa reversible, un pronto inicio de la terapia inmunomoduladora o resección tumoral cuando lo amerite, ha demostrado tener mejor pronóstico a largo plazo con menor riesgo de déficit o secuelas neurológicas.

Dentro de la literatura revisada se logró constatar que la pérdida de lenguaje es un síntoma característico en la población pediátrica, no así la apraxia de la deglución, de la cual no se encontró ninguna referencia bibliográfica, por lo que deberá ser analizado en el futuro con más casos para demostrar su posible asociación.

\section{CONFLICTO DE INTERESES}

Los autores declaran no tener ningún conflicto de intereses relacionados al caso.

\section{REFERENCIAS BIBLIOGRÁFICAS}

1. Ahmad, S., Campen, C. J., Dalmau, J., Davis, R. L., Florance, N. R., Glaser, C. A., . . Zhou, L. (Julio de 2009). Anti-N-Methyl-D-Aspartate Receptor (NMDAR) Encephalitis in Children and Adolescents. Annals Neurology, 1-15.

2. Álvarez, C., Carmona, O., Dalmau, J., Devaud, C., Erazo, R., Gayoso, C., . . Toledo, X. (29 de Julio de 2016). Encefalitis subaguda por anticuerpos anti receptor de N-metil-D-aspartato. Serie de 13 casos pediátricos. Revista Chilena de Pediatría, 87(6), 487-493.

3. Armangue, T., Bataller, L., Dalmau, J., Gabilondo, I., Graus, F., Málaga, I., \& Titulaer, M. J. (Abril de 2013). Pediatric Anti-NMDAR encephalitis-Clinical analysis and novel findings in a series of 20 patients. The Journal of Pediatrics, 162(4), 850-856.

4. Caparó Oblitas, R. L. (Marzo-Abril de 2018). Encefalitis autoinmunes. Un nuevo diagnóstico para una antigua enfermedad. Medicina Buenos Aires, 78, 88-93.

5. Collao Parra, J. P., Delgado Derio, C., \& Romero Urra, C. (Marzo de 2018). Encefalitis autoinmunes: criterios diagnósticos y pautas terapéuticas. Revista Médica de Chile, 146(3), 351.361.

6. Dalmau, J., \& Graus, F. (1 de Marzo de 2018). Antibody-Mediated Encephalitis. (A. H. Ropper, Ed.) The New England Journal of Medicine, fh840-851.

7. Duffy, J. R., Graff-Radford, J., Jones, D. T., Josephs, K. A., Rabinstein, A. A., \& Strand, E. A. (18 de Febrero de 2014). The neuroanatomy of pure apraxia of speech in stroke. brain and Language, 129, 43-46. Recuperado el 27 de Setiembre de 2019. 
8. González-Fernández, M., Hillis, A. E., Mulheren, R. W., Tippett, D., \& Trupe, L. A. (Octubre de 2018). Neural Mechanisms of Swallowing Dysfunction and Apraxia of Speech in Acute Stroke. Dysphagia, 33(5), 610-615. Recuperado el 27 de Setiembre de 2019.

9. Pérez-Aisa, Á., \& Rosales-Zábal, J. M. (21 de Febrero de 2012). Disfagia orofaríngea. RAPD Online, 35(1), 29-35. Recuperado el 5 de Octubre de 2019.

10. Villegas Reyes, José David. (2020). Análisis de la epidemiología, respuesta terapéutica, y pronóstico de los pacientes con Encefalitis Autoinmune en los Hospitales México, San Juan de Dios, Rafael Ángel Calderón Guardia, Maximiliano Peralta Jiménez, Nacional de Niños, en el periodo de febrero 2013 a noviembre 2018 (Tesis de postgrado). Universidad de Costa Rica, Costa Rica. 